\title{
ESPACIALIZAÇÃO DA PRECIPITAÇÃO PLUVIOMETRICA TOTAL ANUAL DA BACIA HIDROGRÁFICA DO ALTO JACUÍ-RS
}

\author{
Jakeline Baratto $^{(a)}$, Cássio Arthur Wollmann ${ }^{(b)}$ \\ (a) Doutoranda do Programa de pós-graduação em Geografia/Bacharel em Geografia, Licencianda em Geografia, \\ Universidade Federal de Santa Maria, jekeline.jake@ hotmail.com \\ (b) Professor do Programa de pós graduação em Geografia/Bacharel em Geográfia, Universidade Federal de Santa \\ Maria, cassio_geo@yahoo.com.br
}

Eixo: 3. Climatologia em diferentes níveis escalares: mudanças e variabilidades

\begin{abstract}
Resumo/
Este trabalho tem como objetivo especializar a precipitação pluviométrica total anual de cada posto pluviométrico da bacia hidrográfica do Alto Jacuí-RS. Com isso, buscou-se dados dos postos pluviométricos localizado na área de estudo e próximo do seu divisor de água. Assim, foram selecionados 27 postos pluviométricos com uma série de dados mensais de janeiro de 1980 a dezembro de 2010, contemplando 31 anos. Após a aquisição dos dados, os mesmos foram tabulados e organizados. Foi utilizado o método de Sturges para determinar o número de classes, sendo estabelecidas diferentes classe para cada cartograma e o Software ArcGIS para a geração das isoietas. Analisando os totais anuais dos 31 anos pode-se perceber que há uma tendência na região central e sudoeste da bacia hidrográfica em concentrarem os menores valores de precipitação pluviométrica. Dessa forma, é compreensível considerar que o efeito orográfico é um fator importantíssimo na variação pluviométrica.
\end{abstract}

Palavras chave: Precipitação pluviométrica, variabilidade, postos pluviométricos, bacia hidrográfica.

\section{Introdução}

A variabilidade climática afeta de forma direta e indireta a vida econômica e social da população, especialmente na geração de energia, atividades agrícolas, indústria, turismo, entre outros. Um dos fenômenos físicos decorrentes dessa variabilidade climática é a precipitação pluvial, que se constitui em um importante fator no controle do ciclo hidrológico, que pode ser considerada uma das variáveis atmosféricas de maior influência na qualidade do meio ambiente. Dessa forma, as quantidades relativas de precipitação pluvial, ou seja, seu volume, seja sazonal ou diário, e as intensidades são algumas das suas características que afetam a população, a economia e o meio ambiente (BRITTO et al., 2006).

Portanto, conhecer essa dinâmica pluvial é de suma importância para a solução de problemas referentes aos períodos chuvosos e menos chuvosos, bem como, evitar os problemas referentes aos eventos extremos de precipitação, que resultam na entrada de sedimentos nos reservatórios, diminuindo sua vida útil. 


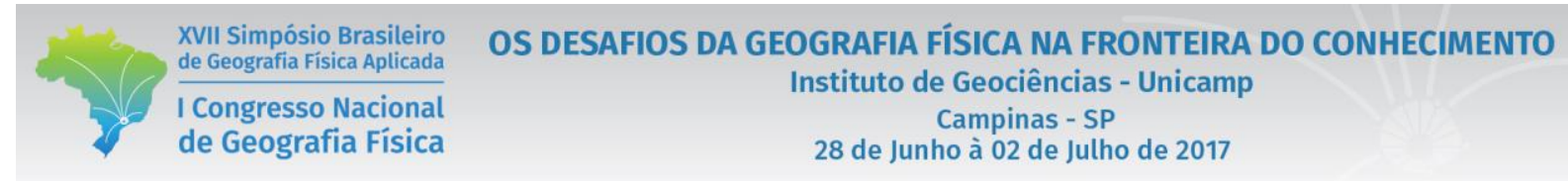

Além disso, a bacia hidrográfica está diretamente ligada à dinâmica do setor agropecuário, fazendo com que os eventos adversos de precipitação afetem a economia da região, trazendo na maioria das vezes prejuízos. Dessa forma, conhecer a dinâmica da precipitação auxilia no gerenciamento de bacias hidrográficas e seu recurso hídrico, fornecendo ao ordenamento do território meios para melhor avaliar os impactos das atividades humanas empregadas. Contudo, o objetivo deste trabalho é especializar a precipitação pluviométrica total anual de cada posto pluviométrico da bacia hidrográfica do Alto JacuíRS.

\section{Materiais e métodos}

A área de estudo é a bacia hidrográfica do Alto Jacuí que abrange uma área de $12.985,44 \mathrm{~km}^{2} \mathrm{e}$ está localizada na região hidrográfica do Guaíba. A bacia hidrográfica do Alto Jacuí possui grande variação altimétrica, correspondendo de $85 \mathrm{~m}$ a $776 \mathrm{~m}$ acima do nível do mar. Na bacia hidrográfica do Alto Jacuí estão inseridos 42 municípios (Figura 1).

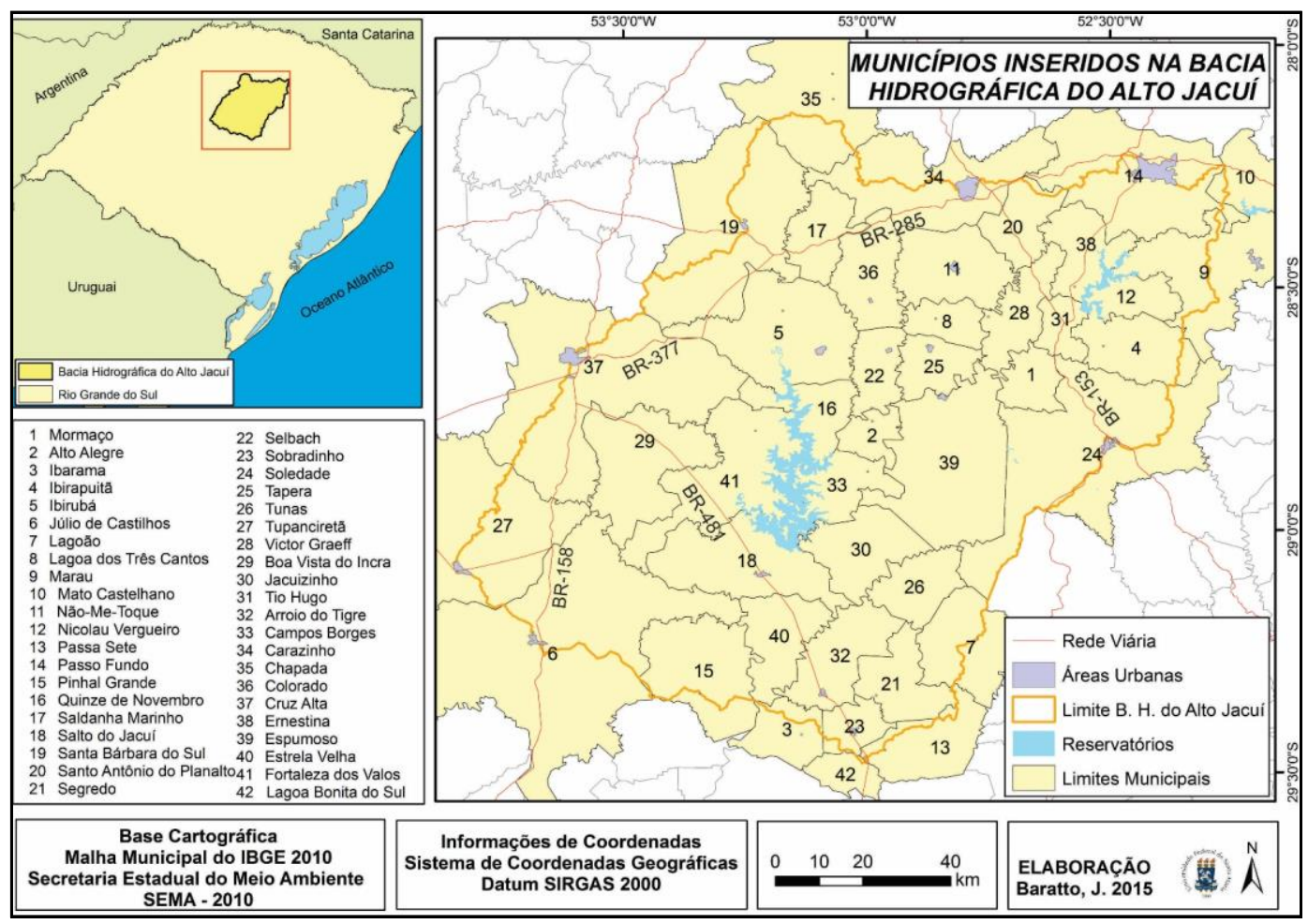

Figura 1 - Localização da área de estudo 
A aquisição dos dados para está pesquisa de estabeleceu a partir de dados dos postos pluviométricos controlados pela Companhia Estadual de Energia Elétrica Geração e Transmissão (CEEE-GT) e da Agência Nacional das Águas (ANA), também foram utilizados dados pluviométricos da estação meteorológica da Fundação Estadual de Pesquisa Agropecuária (Fepagro). Com isso se estabeleceu dois critérios para a seleção dos postos, o primeiro é a continuidade das informações nas bases de dados pluviométricos e nos anos; e abrangência da bacia hidrográfica de interesse. Assim, foram selecionados 27 postos pluviométricos com uma série de dados mensais de janeiro de 1980 a dezembro de 2010, contemplando 31 anos.

Após a aquisição dos dados, os mesmos foram tabulados e organizados. Nesta fase de análise preliminar dos dados pluviométricos pode-se notar algumas falhas. Para o preenchimento das falhas na série histórica da bacia hidrográfica do Alto Jacuí, precisou-se primeiramente identificar o dado faltante em cada posto, ao proceder esta assimilação, o referido mês e ano que não contivesse o registro, precisou-se encontrar o posto vizinho de menor distância, o qual seria coletado o dado real para o preenchimento das falhas do posto faltante.

Para a espacialização da distribuição pluviométrica da bacia hidrográfica do Alto Jacuí foram organizadas no Microsoft Office Excel 2013 tabelas referentes a precipitação pluviométrica total anual de cada ano em análise. Ainda no referido software foi necessário determinar o número de classes que cada cartograma. Assim, foi utilizado o método de Sturges para determinar o número de classes, sendo estabelecidas diferentes classe para cada cartograma.

Em relação a precipitação pluviométrica total anual foram estabelecidas onze classes com intervalos iguais de $188 \mathrm{~mm}$ sendo elas, 888 - $1076 \mathrm{~mm} ; 1077$ - $1265 \mathrm{~mm} ; 1266$ - $1454 \mathrm{~mm} ; 1455$ - $1643 \mathrm{~mm}$; 1644 - 1832 mm; 1833 - 2021 mm; 2022 - 2210 mm; 2211 - 2399 mm; 2400 - 2588 mm; 2589 - 2777mm; 2778 - 2966 $\mathrm{mm}$.

Após a classificação dos intervalos das classes as planilhas contendo as precipitações pluviométricas foram importadas ao Software ArcGIS 10.1, desenvolvido pela ESRI. Assim, para cada cartograma foi criado uma planilha contento as coordenadas de cada ponto e a sua precipitação, criando-se uma planilha para a precipitação pluviométrica total anual.

Por meio do programa computacional (ArcGIS 10.1), foram geradas as isoietas pelo método de interpolação geoestatística krigagem ordinária, cujo modelo de semiovariograma utilizado foi o esférico, pois segundo Wollmann (2011) a krigagem ordinária é um método muito utilizado para a espacialização de dados climáticos. 


\section{Resultados}

Os totais anuais foram separados em três décadas para a melhor análise dos dados, a primeira década corresponde os anos de 1980 a 1989, a segunda de 1990 a 1999 e a última de 2000 a 2010, tendo está última 11 anos de análise.

No ano de 1980 o posto 19 obteve a menor precipitação total anual com 1344,7mm. O posto 25 atingiu a maior precipitação total $(1847,8 \mathrm{~mm})$. Sendo a variação da precipitação para o ano de $503,1 \mathrm{~mm}$. Neste ano período no setor norte da bacia hidrográfica ocorreram os maiores volumes de precipitação total, com valores entre 1644-1832mm, na região central da mesma, os valores de chuva variam entre 1455-1654mm. Na região sul da bacia hidrográfica a precipitação total anual varia entre $1266-1454 \mathrm{~mm}$, sendo os menores valores de precipitação, bem como, as menores altitudes.

No ano de 1981 o posto como a maior precipitação foi o 10, alcançando 1577,0mm, enquanto que o posto 19 obteve a menor precipitação total $(1027,8 \mathrm{~mm})$ entre totais anuais, sendo observada uma variação entre os postos de 449,2mm. Na região sudoeste da bacia hidrográfica o total anual de cada posto variou entre 888-1107mm, sendo os menores valores de precipitação. Na região central da bacia hidrográfica foi possível observar uma ilhota com variação entre 1077-1265mm. Na maior área da bacia hidrográfica ocorreram chuvas entre 1266-1454mm, assim, este ano a precipitação aumentou de sudoeste para norte.

Em 1982, o posto 27 alcançou a maior precipitação total, com 2439,2mm e o posto 13 obteve a menor precipitação total com $1657,8 \mathrm{~mm}$. Sendo a variação entre os postos de $781,4 \mathrm{~mm}$, neste ano, a precipitação pluviométrica total anual variou no intervalo de $2022-2210 \mathrm{~mm}$ para toda a bacia. O posto 20 alcançou a maior precipitação total para o ano de 1983 com 2626,4mm, enquanto que o posto 22 obteve a menor precipitação total com 1936,2mm, sendo a variação entre os pontos de 690,2mm. O setor norte da bacia hidrográfica e uma pequena área no divisor d'água na região leste da mesma, atingiram os maiores valores de precipitação total, com variação entre $2589-2777 \mathrm{~mm}$. Na região central ocorreram chuvas totais entre 2400-2588mm. Já no setor e sudoeste ocorreram as menores precipitações com 2022-2210mm.

No ano de 1984, o posto 23 atingiu a maior precipitação total com 2489,2mm, enquanto que a menor precipitação total foi registrada no posto 12, para este ano. A variação da precipitação neste período foi de 576,3mm. Na região central, próximo aos pontos P08, P09 e P21, ocorreram as menores precipitações totais variando entre $1830-2021 \mathrm{~mm}$, a maior região da bacia hidrográfica tem precipitação entre 20222210mm. Nas áreas próximas ao divisor d'água ocorreram, para este ano, as maiores precipitações com 2211-2399mm, conforme mostra a figura 2. 


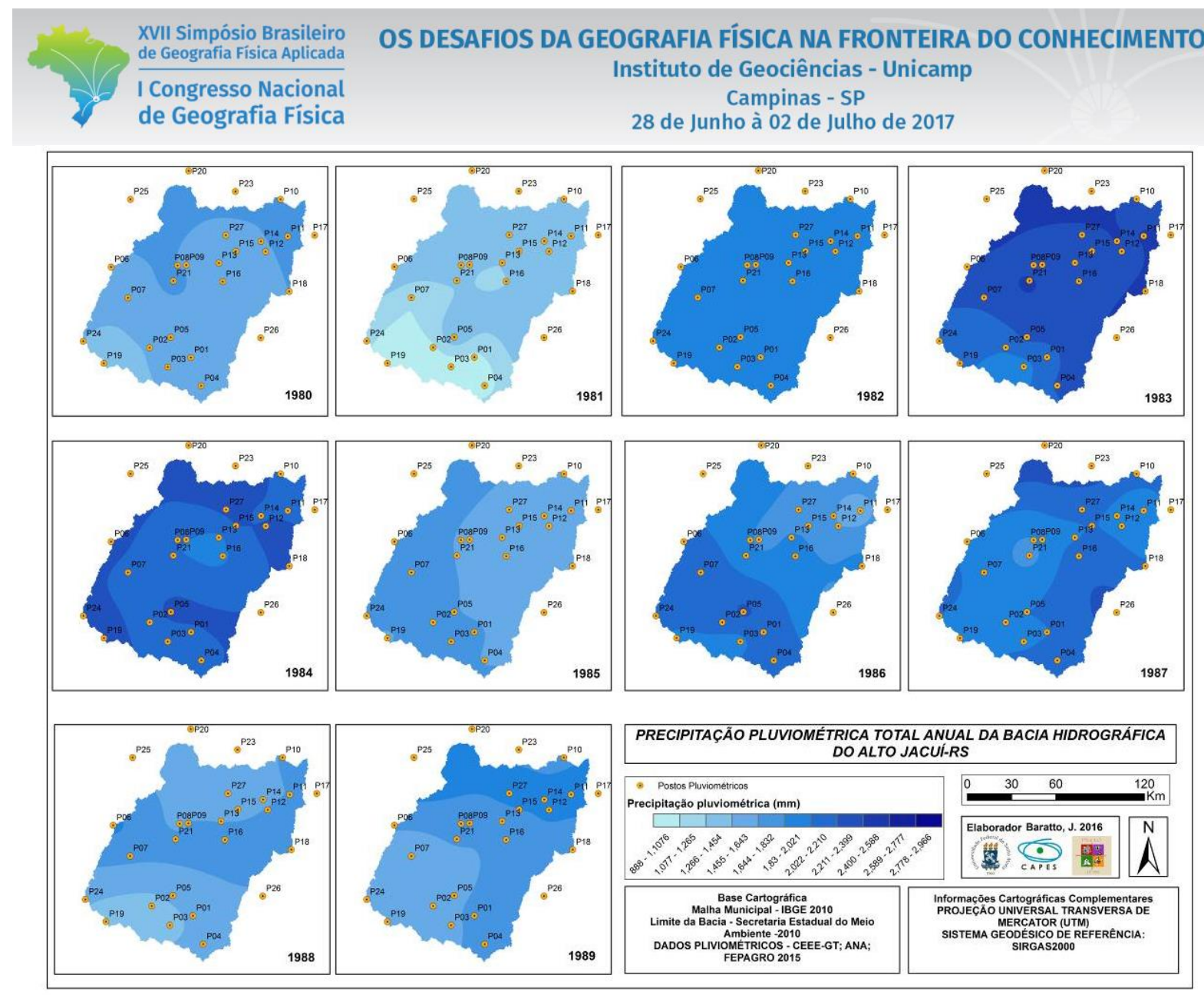

Figura 2 - Distribuição da precipitação pluviométrica da primeira década de análise

No ano de 1985 o posto 25 alcançou a maior precipitação total (2022,3mm), enquanto que posto 13 , com $1303,2 \mathrm{~mm}$, foi o que obteve a menor precipitação, sendo a variação para este ano de $639,1 \mathrm{~mm}$. Na espacialização dos dados totais anuais as maiores precipitações ocorreram no oeste da área de estudo, com a variação pluviométrica entre $1644-1832 \mathrm{~mm}$. Na região leste da bacia hidrográfica ocorreram os menores totais pluviométricos com 1455-1643mm.

No ano de 1986 o posto 05 alcançou a maior precipitação total, sendo de $2253,4 \mathrm{~mm}$. E o posto 11 com a menor precipitação. A variação entre os postos foi de $707,5 \mathrm{~mm}$. O setor nordeste da bacia hidrográfica obteve a menor precipitação total com variação entre 1455-1832mm. Os maiores volumes totais estendem-se numa faixa de sul a oeste, com valores que variam entre 2022-2210mm.

Em 1987, o posto 23 alcançou a maior precipitação total com $2351,8 \mathrm{~mm}$. E o posto 21 como a menor precipitação, com 1756,6mm, sendo a variação entre os postos de 595,2mm. Neste ano, pequenas áreas na região norte, oeste e leste ocorreram os maiores totais de precipitação pluviométrica, com 2211-2399mm. Na região central da bacia hidrográfica ocorreram os menores totais pluviométricos, com variação entre $1644-1832 \mathrm{~mm}$. 
No ano de 1988 o posto 06 obteve a maior precipitação total, com 1935,8mm e o posto 02 a menor precipitação pluviométrica total. Cuja variação entre os dois postos foi de $597,2 \mathrm{~mm}$. Na região sudoeste ocorreram os menores totais anuais com 1077-1256mm. No setor central o maior valor total anual, com $1455-1643 \mathrm{~mm}$.

No ano 1989 o posto 25 alcançou a maior precipitação, em contrapartida o posto 03 obteve a menor, sendo 2152,5 mm para a maior precipitação e 1468,9 mm para a menor. Assim, a variação entre os postos foi de $683,6 \mathrm{~mm}$. Na região norte ocorreram os maiores valores totais anuais com precipitação entre 1644$1832 \mathrm{~mm}$, já os menores totais anuais localizam-se na região sudoeste-oeste, com 1266-1454mm.

Nesta primeira década de análise dos dados pluviométricos totais anuais os anos mais chuvosos foram 1983 e 1984 e os menos chuvosos foram os de 1981 e 1988. Nessa análise mostrou que há um comportamento similar dos dados totais anuais, sendo que, na maioria dos anos os menores valores de precipitação se encontram na região sudoeste da bacia hidrográfica e os maiores valores na região norte, evidenciando assim, a influência da altitude e das Frentes Frias na distribuição das chuvas, bem como ressaltado por Sartori (1993, 2003) e Rossato (2011).

Na segunda década de análise, o ano de 1990, o posto 25 atingiu a maior precipitação pluviométrica total de $2862,0 \mathrm{~mm}$, enquanto que o posto 07 obteve a menor precipitação com 1728,6mm. Esse ano foi um dos que ocorreu a maior variação entre os postos com 1133,4mm. Neste ano, pequenas áreas da região norte alcançaram a maior precipitação para o período com $2589-2777 \mathrm{~mm}$. Nas porções sul e sudoeste ocorreram as menores precipitações para a bacia, assim a precipitação variou entre $1644-1832 \mathrm{~mm}$.

No ano de 1991 o posto 26 alcançou a maior precipitação total, com 1677,6mm enquanto que o posto 21 obteve a menor precipitação pluviométrica, com $991,2 \mathrm{~mm}$. A variação para este ano foi de $686,4 \mathrm{~mm}$, na região central da bacia hidrográfica ocorreram os menores valores de precipitação total anual, com variação de $888-1107 \mathrm{~mm}$. No setor noroeste e leste concentraram os maiores totais com $1266-1454 \mathrm{~m}$, sendo o ano classificado como ano-padrão menos chuvoso.

Em 1992, que foi classificado como ano-padrão habitual, o posto 10 atingiu a maior precipitação total com $2286,3 \mathrm{~mm}$. Já o posto 24 obteve a menor precipitação total com 1447,1 mm. Sendo a variação entre os postos de $839,2 \mathrm{~mm}$. Por conta destes dados, este ano foi classificado como ano-padrão habitual, os menores valores de precipitações foram registrados na região sudoeste a bacia, já na região nordeste ocorreram os maiores valores de precipitação total.

O ano de 1993 o posto 25 alcançou a maior precipitação para o ano, com 2150,0mm, enquanto que a menor precipitação total ficou no posto 21 , a variação entre esses postos foi de $639,0 \mathrm{~mm}$. Neste ano na região central ocorreram as menores precipitações totais com 1454-1643mm. Nas porções noroeste e oeste 
ocorreram as maiores precipitações para a bacia, com precipitação total anual entre $1833-2021 \mathrm{~mm}$, conforme figura 3.

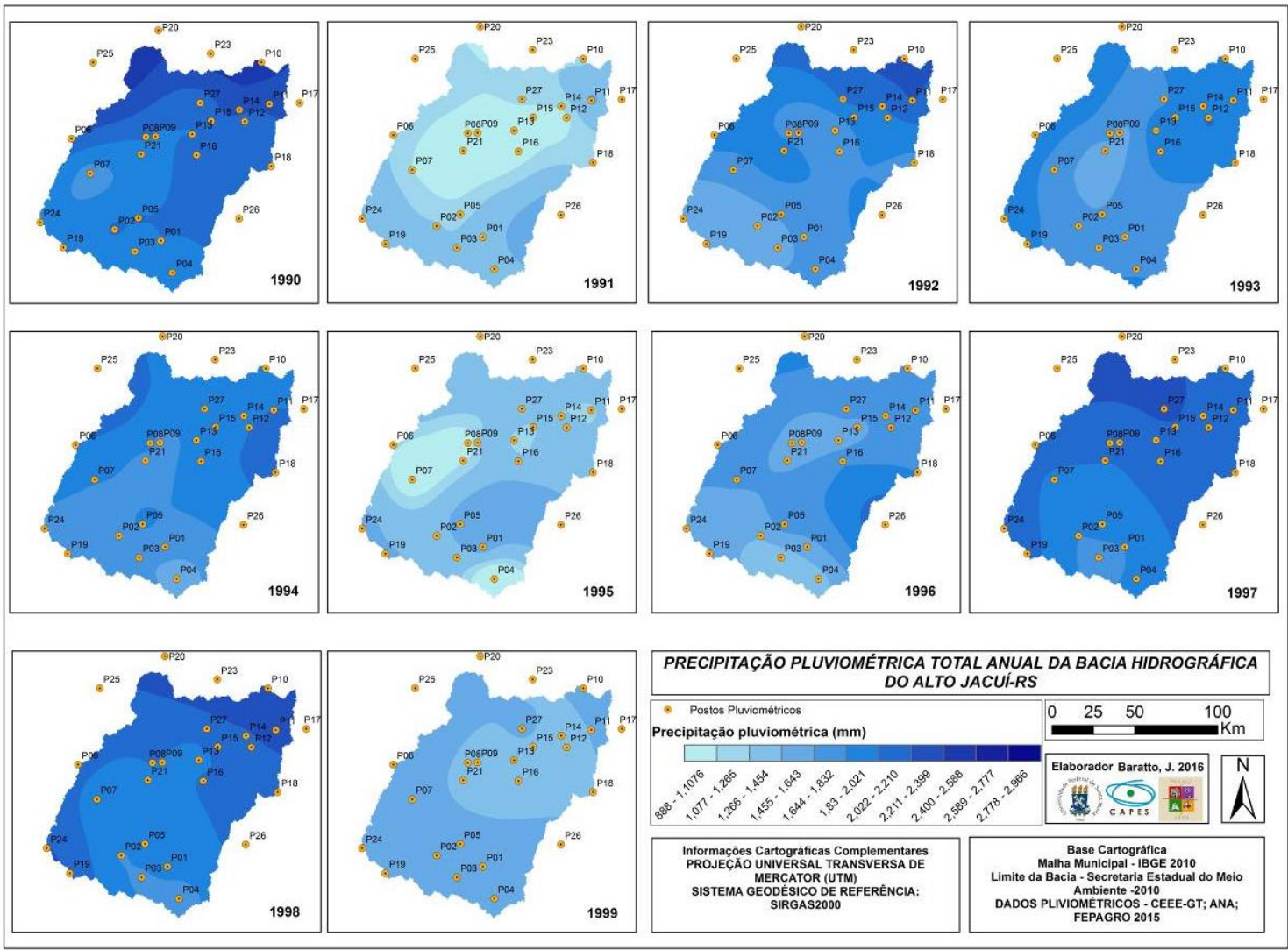

Figura 3 - Distribuição da precipitação pluviométrica da segunda década de análise

O posto 25 , no ano de 1994 , continuou sendo o posto de maior precipitação total com $2293,9 \mathrm{~mm}$, enquanto que o posto 04 obteve a menor precipitação para este ano. Sendo a variação entre estes postos $832,1 \mathrm{~mm}$. No ano de 1994 a menor precipitação concentrou-se na região sul da bacia. Em pequenas áreas no setor leste e oeste da bacia hidrográfica ocorreram as maiores precipitações totais, com 2022-2210mm. No ano de 1995, o posto 22 atingiu a maior precipitação total, enquanto o 04 continuou sendo o posto de menor precipitação com $888,2 \mathrm{~mm}$, com uma variação entre de 778,2mm. Os menores valores de precipitação total para o ano de 1995 estão localizados na região oeste da bacia, com valores que variam entre $888-1107 \mathrm{~mm}$, no setor leste da bacia hidrográfica concentram os maiores valores de precipitação com 1455-1643mm. Nesse ano foi possível observar pequenas ilhotas com precipitação total de 1077 $1265 \mathrm{~mm}$. 
Em 1996, o posto 26 alcançou a maior precipitação total, com 2187,2mm, enquanto o posto 03 obteve a menor precipitação total de $1338,8 \mathrm{~mm}$, sendo a variação entre os postos de $848,4 \mathrm{~mm}$. No setor sul da bacia hidrográfica ocorreram as menores precipitações com 1077-1265mm, o setor leste acumulou as maiores precipitações pluviométricas com 2022-2210mm e no central da bacia hidrográfica foi possível observar uma ilhota com precipitação variando de 1266-1454mm.

No ano de 1997 o posto 27 atingiu a maior precipitação, sendo ela, de 2421,1mm, enquanto a menor precipitação total para este ano na bacia hidrográfica foi apresentada pelo posto 03 , com uma variação pluviométrica entre os pontos de $764,7 \mathrm{~mm}$. Na espacialização dos dados no setor norte concentraram as maiores precipitações totais anuais, com variação de 2211-2399mm, no setor sul da bacia hidrográfica ocorreram os menores valores totais anuais, com precipitação variando de 1455-1643mm. Em 1997 a distribuição da precipitação estabeleceu os menores valores totais anuais na parte sul, para o norte com os maiores totais anuais.

Em 1998, o posto 23 alcançou a maior precipitação pluviométrica com 2411,6mm, enquanto que o 04 obteve a menor precipitação total, com uma variação entre os pontos de $711,2 \mathrm{~mm}$. O comportamento da distribuição das chuvas para o ano de 1998 foi semelhante ao do ano anterior, sendo o setor sul com os menores valores totais anuais e o norte com os maiores valores, sendo os maiores valores variando entre 2211-2399mm e os menores valores entre 1455-1643mm.

No ano de 1999, o posto 24 alcançou a maior precipitação total $(1690,0 \mathrm{~mm})$, enquanto que o posto 03 obteve a menor precipitação total com $12903 \mathrm{~mm}$. Neste ano ocorreu a menor variação da precipitação pluviométrica, sendo de $339.7 \mathrm{~mm}$, ao contrário dos dois últimos anos. Ainda no ocorrente ano, os maiores totais registrados ocorreram na região sul da bacia hidrográfica com precipitação entre 1455-1643mm, já a região centro-norte concentrou as menores precipitações totais com variação entre 1266-1454mm.

De maneira geral, nessa segunda década de análise pode-se verificar que a região central obteve os menores valores das precipitações totais, enquanto que os maiores totais de precipitação concentraram na região norte da bacia hidrográfica onde estão as nascentes dos principais rios que drenam a mesma, com as do Rio Jacuí-mirim, Rio Glória, Rio Jacuí. Assim, nessa década não se pode evidencia a influência das Frentes Frias na distribuição da precipitação total anual dos postos pluviométricos, mostrando-se dessa forma um comportamento diferenciado da década anterior.

Na terceira década de análise (figura 4), no ano 2000, o posto 20 alcançou a maior precipitação total com $2151,9 \mathrm{~mm}$, já o posto com a menor precipitação total para a bacia hidrográfica foi o $21 \mathrm{com}$ 1213,6mm, com uma variação pluviométrica de $938,3 \mathrm{~mm}$. Na espacialização dos dados totais anuais pode-se perceber que no setor central da bacia hidrográfica ocorreram as menores precipitações com variação entre 1226- 
$1454 \mathrm{~mm}$, enquanto que os maiores valores localizaram-se em pequenas áreas no setor norte, leste e sul da mesma, sendo os valores nessas áreas, variando entre 1644-1832mm.

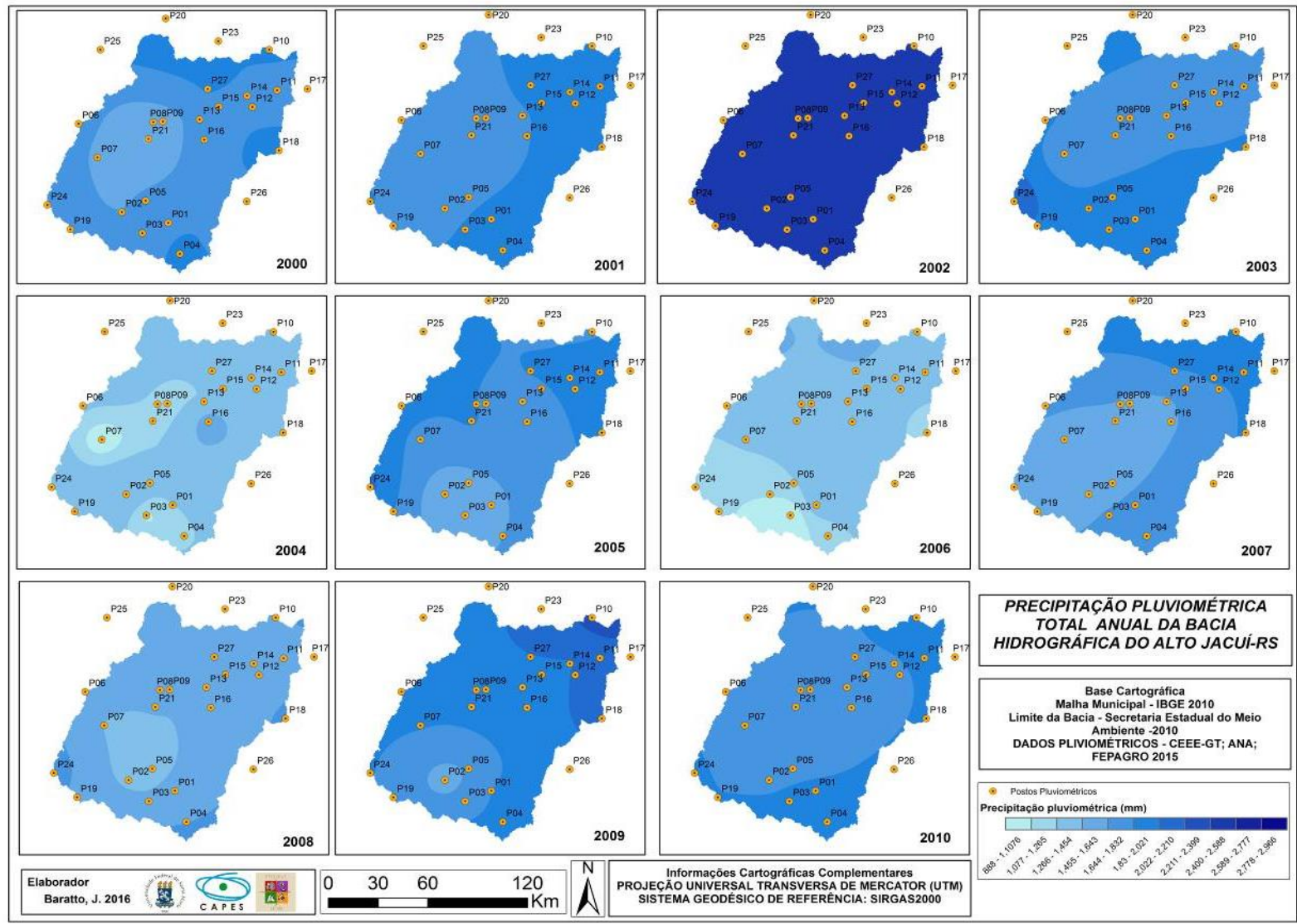

Figura 4 - Distribuição da precipitação pluviométrica da terceira década de análise

No ano de 2001 o posto 24 alcançou a maior precipitação total com $2326,2 \mathrm{~mm}$ e o posto de menor precipitação foi o 19 com $1128,8 \mathrm{~mm}$. A variação pluviométrica nesse ano foi a maior registrada nos últimos 31 anos, com 1197,4 mm de diferença entre os pontos. No setor oeste da bacia hidrográfica ocorreu os menores valores totais de precipitação com variação entre 1644-1832mm, já no setor leste da bacia, os totais anuais de chuva variaram entre $1833-2021 \mathrm{~mm}$.

Em 2002, que foi considerado o ano-padrão mais chuvoso, o posto 24 alcançou a maior precipitação total com 2961,2mm, bem como no ano anterior, o 03 foi o de menor precipitação pluviométrica, com 2611,6mm, a variação espacial das chuvas ficou entre as classes de 2778-2966mm. Assim, toda a bacia hidrográfica obteve uma pluviometria elevada, confirmando como sendo o ano mais chuvoso da mesma. Na Figura 40, é possível observar a precipitação pluviométrica da terceira década de análise. 
No ano de 2003, o posto 24 alcançou a maior precipitação total com $2426,6 \mathrm{~mm}$ e o posto de menor precipitação foi o posto 07 com 1433,5mm, a variação pluviométrica no ano foi de 993,1mm e as maiores totais anuais estão entre 2022-2210mm, localizado no setor sudoeste da bacia, próximo ao posto 24 , enquanto que os menores valores de chuva estão na região centro-norte da bacia hidrográfica com uma precipitação de $1644-1832 \mathrm{~mm}$.

No ano de 2004, o posto 16 alcançou a maior precipitação total com 1640,3mm e o posto de menor precipitação, como no ano anterior, continuou sendo o posto 07 com 1011,9mm, apresentou uma variação pluviométrica de $628,4 \mathrm{~mm}$. Neste ano, o setor oeste da bacia hidrográfica concentrou os menores volumes precipitados com 888-1076mm, enquanto que na maior parte da bacia hidrográfica ocorreu uma precipitação entre 1266-1454mm. O maior volume precipitado concentrou-se próximo ao posto 16.

Em 2005 o posto 24 alcançou a maior precipitação total com $2298,9 \mathrm{~mm}$, já o posto de menor precipitação foi o 02 com $1269,6 \mathrm{~mm}$, a variação pluviométrica nesse ano foi de $029,3 \mathrm{~mm}$. Neste ano os maiores valores de precipitação ocorreram no setor oeste e leste da bacia, cujo valores variam entre 1833-2021mm, enquanto que os menores valores totais concentraram na região sul da bacia, com 1266-1454mm.

No ano de 2006, o posto 23 alcançou a maior precipitação total com 1563,7mm, já o de menor precipitação continuou sendo o posto 03, com 1038,1mm, a variação pluviométrica no ano foi de $525,6 \mathrm{~mm}$. No setor sudoeste da bacia hidrográfica ocorreram os menores totais pluviométricos com variação de 888-1106mm e no setor norte da mesma ocorreram os maiores volumes totais com 1455$1643 \mathrm{~mm}$. A região central da bacia hidrográfica a precipitação total anual variou entre 1266-1454mm, assim, a precipitação pluviométrica se estabeleceu de sudoeste pra norte.

Em 2007 o posto 26 obteve a maior precipitação total com 2075,9mm e o posto de menor precipitação continuou sendo o posto 05 , com $1411,0 \mathrm{~mm}$, a variação pluviométrica no ano foi de $664,9 \mathrm{~mm}$. Neste ano os menores totais de precipitação se localizaram na região sudoeste, com variação de $1455-1643 \mathrm{~mm}$. E os maiores totais se localizam na região nordeste, com precipitação que variam de $1833-2021 \mathrm{~mm}$.

Em 2008 o posto 22 atingiu a maior precipitação total com 2072,7mm, enquanto que o posto de menor precipitação foi o 05 com 1203,4mm, o que gerou uma variação pluviométrica de $869,3 \mathrm{~mm}$ Neste ano a maior parte da bacia hidrográfica obteve a precipitação pluviométrica variando entre 1455-1643mm, pequenas áreas da região sul, leste e oeste apresentaram oscilação que ficaram entre 1644-1832mm, as quais foram os mais altos índices registrados no ano, já as menores precipitações ocorreram na região central da bacia, próximas aos postos P02, P05 e P07, com registro variando entre 1266-1454mm.

No ano de 2009 o posto 10 alcançou a maior precipitação total com 2358,4mm, enquanto que o menor índice foi o registrado pelo posto 02, com 1407,4mm, a variação pluviométrica no ano foi de 951,0mm. A precipitação total anual concentrou na região sul os menores valores, com variação entre $1455-1643 \mathrm{~mm}$, 
enquanto que na região nordeste ocorreram os maiores valores precipitados com 2211-2399mm. Assim, o comportamento das chuvas para este ano foi de sudoeste para nordeste.

Em 2010 o posto 22 obteve a maior precipitação total com 2421,0mm. E o posto de menor precipitação foi o posto 13 , com $1471,6 \mathrm{~mm}$, a variação pluviométrica no ano foi de $949,4 \mathrm{~mm}$. No último ano de análise dos totais anuais, pode-se perceber que na região central da bacia hidrográfica ocorreram os menores totais entre 1644-1832mm, já na região sul, leste e norte concentram os maiores totais com variação de 1833- $2021 \mathrm{~mm}$.

Nessa última década pode-se observar a tendência de a região centro-sul ser menos chuvosas continua, na maioria dos anos. Sendo que a região norte e nordeste possui uma leve tendência a ser mais chuvosa nessa década. Porém não existe uma regularidade na distribuição espacial das chuvas para essa década.

\section{Conclusão}

Analisando os totais anuais dos 31 anos pode-se perceber que há uma tendência na região central e sudoeste da bacia hidrográfica em concentrarem os menores valores de precipitação pluviométrica. Com exceção, dos anos de 1982 e 2002 que tiveram uma precipitação homogênea em todo a bacia, assim, observa-se que a precipitação total anual para a bacia hidrográfica do Alto Jacuí na maioria dos anos tem uma orientação de sudoeste para nordeste, sendo que, sudoeste tem os menores totais e em nordeste os maiores totais anuais. Porém ao analisar cada ano separadamente não existe uma homogeneidade na distribuição espacial da precipitação pluviométrica total anual, assim, cada ano a precipitação ocorre de maneira diferenciada, principalmente nos dados de maior precipitação total. Contudo, a uma tendência da região central e sul ser a menos chuvosa na maioria dos anos.

Com isso, é possível considerar que existe uma grande variação na distribuição espacial das chuvas em função da orografia na bacia hidrográfica do Alto Jacuí. Foi possível identificar que a localização geográfica da bacia, contém uma grande variação hipsométrica ao longo da sua extensão fazendo-se que haja esta grande variação na distribuição espacial das chuvas em função da orografia na bacia. Dessa forma, é compreensível considerar que o efeito orográfico é um fator importantíssimo na variação pluviométrica. Porém, há uma tendência na região central e sudoeste a ter os menores valores. Assim, observa-se que a precipitação total anual para a bacia hidrográfica do Alto Jacuí na maioria dos anos tem uma orientação de sudoeste para nordeste, sendo que, sudoeste tem os menores totais e em nordeste os maiores totais anuais. 


\section{Referencias}

BRITTO, F. P.; BORLETTA, R.; MENDONÇA, M. Regionalização sazonal e mensal da precipitação pluvial máxima no estado do Rio Grande do Sul. Revista Brasileira de Climatologia, Vol. 2, p. 35-51, dez. 2006.

COMITE DE GERENCIAMENTO DA BACIA HIDROGRÁFICA DO ALTO JACUÍ. Plano de Bacia. Carazinho, 2016. Disponível em: <http://www.coaju.com.br/plano_de_bacia〉. Acesso em: Jan. 2016.

HASENACK, H.; WEBER, E.(org.) Base cartográfica vetorial contínua do Rio Grande do Sul - escala 1:50.000. Porto Alegre: UFRGS Centro de Ecologia. 2010. 1 DVD-ROM. (Série Geoprocessamento n.3). ISBN 978-85-6348300-5 (livreto) e ISBN 978-85-63843-01-2 (DVD).

INMET - Instituto Nacional de Meteorologia. MAPA- Ministério da Agricultura, Pecuária e Abastecimento. Normais Climatológicas do Brasil 1961 -1990. Edição revista ampliada. Brasília, 2009. 253p.

ROSSATO. M. S. Os climas do Rio Grande do Sul: variabilidade, tendências e tipologia. 2011. 253 f. Tese (Doutorado em Geografia) - Universidade Federal do Rio Grande do Sul, Porto Alegre, 2011.

SARTORI, M. da G. B. A Circulação Atmosférica Regional e os Principais Tipo de Sucessão do Tempo no Inverno do Rio Grande do Sul, RS. Ciência e Natura, UFSM, 15: 69-93, 1993a.

SARTORI, M. da G. B. A dinâmica do clima no Rio Grande do Sul: indução empírica e conhecimentos científicos. Terra Livre, São Paulo, Ano 19, vol. I, n. 20, p. 27-49,jan./jul. 2003.

WOLlmanN, C. A. Zoneamento Agroclimático para a Produção de Roseiras (Rosaceae spp.) no Rio Grande do Sul. Tese (Doutorado em Geografia Física). Universidade de São Paulo. 2011. 382p. 2. V. 